\title{
Interval and continuous aerobic exercise training similarly increase cardiac function and autonomic modulation in infarcted mice
}

\author{
Cesar Cavinato Cal Abad',* , Ademir Manuel do Nascimento', Leandro Eziquiel dos Santos', Diego Figueroa', Pamella Ramona', \\ Michele Sartori', Katia B. Scapini', Oscar Albuquerque', Ivana Cinthya Moraes-Silva', Hélio José Coelho-Júnior², Bruno Rodrigues², \\ Cristiano Teixeira Mostarda ${ }^{1,3}$, Kátia De Angelis ${ }^{4}$, Maria Cláudia Irigoyen ${ }^{1}$
}

'Hypertension Unit, Heart Institute (InCor), University of Sao Paulo Medical School, São Paulo, Brazil

${ }^{2}$ Faculty of Physical Education, University of Campinas (UNICAMP), Campinas, Brazil

${ }^{3}$ Federal University of Maranhão (UFMA), São Luiz, Brazil

${ }^{4}$ Translational Physiology Laboratory, Nove de Julho University (UNINOVE), São Paulo, Brazil

The present study aimed to compare the effects of moderate-intensity continuous and high-intensity interval exercise training (ET) on exercise tolerance, cardiac morphometry and function, hemodynamic, and cardiac autonomic modulation in myocardial infarcted mice. Wild-type mice (WT) were divided into four groups: sedentary WT (S); WT myocardium infarction sedentary (IS); WT myocardium infarction underwent to moderate-intensity continuous ET (MICT), and WT myocardium infarction underwent to high-intensity interval ET (MIIT). After 60 days of descending coronary artery ligation, moderate-intensity continuous ET consisted of running at $60 \%$ of maximum, while the high-intensity interval training consisted of eight sprints of 4 min at $80 \%$ of maximum and a 4 -min recovery at $40 \%$ of maximum. Both exercises were performed $1 \mathrm{hr}$ a day, 5 days a week, during 8 weeks. Results demonstrated

\section{INTRODUCTION}

Myocardial infarction (MI) is defined as the death of myocardial myocytes due to prolonged ischemia (Alpert et al., 2000). It is one of the most common causes of cardiac morbid-mortality worldwide and brings important impacts on public health (Anand et al., 2008; Finegold et al., 2013). MI affects not only the heart, but also several other physiological systems (e.g., musculoskeletal system), consequently, impairing exercise tolerance, quality of life and health (Thygesen et al., 2012).

To comprehend MI pathophysiology and treatment, animal that IS showed elevated exercise tolerance, as well as decreased hemodynamic and heart function, and autonomic control. On the other hand, both programs of ET were equally effective to increase all parameters, without further differences between the groups. In conclusion, the results of the present study showed that myocardial infarction leads to damage in both investigated strains and the two types of physical exercise attenuated the major impairments provoked by myocardial infarction in exercise tolerance, cardiac structure, cardiac function, hemodynamic and cardiac autonomic modulation.

Keywords: Autonomic modulation, Heart rate variability, Myocardial infarction, Mice, Exercise training, Cardiac function
*Corresponding author: Cesar Cavinato Cal Abad (iD http://orcid.org/0000-0003-4988-5076 Hypertension Unit, Heart Institute (InCor), University of Sao Paulo Medical School, Av. Dr. Enéas de Carvalho Aguiar, 44, São Paulo - SP, 05403-900, Brazil Tel: +55-11-2661-5006, Fax: +55-11-3082-2354, E-mail: c.cavinato@uol.com.br Received: January 31, 2017 / Accepted: April 15, 2017 models of heart ischemia have been extensively used in experimental studies (Tarnavski et al., 2004). In addition, exercise training (ET) — defined as a planned, structured and repetitive bodily movement aimed to maintain or improve one or more components of physical fitness (Caspersen et al., 1985) - has been also considered an inexpensive, non-pharmacological and profitable tool for cardiac rehabilitation (Fletcher et al., 2013; Garza et al., 2015; Hamm et al., 2013).

Although moderate-intensity continuous endurance ET (MICT) seems to be the most accepted and recommend type of exercise for cardiac rehabilitation programs (Mezzani et al., 2013), the optimal 
ET prescription to elicit maximal outcomes for $\mathrm{MI}$ is still under debate (Lu et al., 2015; Moreira et al., 2013). Indeed, evidence have been indicating some advantageous for MICT (Pinho et al., 2012). Whereas, other data have been indicating that high-intensity interval ET (HIIT) — which is conceptually accepted as a relatively brief session of intermittent exercise that alternate among a high-intensity effort and a passive or active rest of the same or approximate duration - can elicit larger beneficial outcomes after MI, in comparison with MICT (Elliot et al., 2015; Keteyian et al., 2014; Lu et al., 2015; Maiorana, 2012). However, others experiments did not find differences between continuous or interval protocols of ET (Nunes et al., 2015; Pattyn et al., 2016; Tschentscher et al., 2016), indicating that more data about this specific issue are necessary. Despite of previous results from experiments with rodents and humans, studies comparing the effects of moderate and high-intensity endurance ET in mice are still limited.

Regarding clinical features of MI, several evidence have been indicating that functional alterations on autonomic function should be one of the main concerns in MI, since the relative mortality risk in infarcted patients was 5.3 times higher in low heart rate variability (HRV) $(50 \mathrm{msec})$ patients than in high-HRV patients (100 msec ) (Kleiger et al., 1987). Moreover, MI patients with lower values $(<3.0 \mathrm{msec} / \mathrm{mmHg}$ ) of baroreflex sensitivity $(\mathrm{BrS})$ showed increased cardiac mortality risk in comparison with higher-BrS patients (La Rovere et al., 1998). In MI rats, studies from our laboratory also found impaired cardiac autonomic function after MI, whereas MICT elicits increase on the autonomic response, as well as reduces significantly mortality rate (Barboza et al., 2013; Mostarda et al., 2010; Rodrigues et al., 2014c). On the other hand, results regarding the effects of ET on cardiac autonomic modulation are limited to non-infarcted mice (De Angelis et al., 2004), such that the effects of moderate-intensity continuous and high-intensity endurance ET on autonomic nervous systems were not investigated previously in MI mice.

Therefore, the present study aimed to compare the effects of continuous and high-intensity interval ET on exercise tolerance, cardiac morphometry and function, hemodynamic, and cardiac autonomic modulation in infarcted mice.

\section{MATERIALS AND METHODS}

\section{Animals}

Sixty-eight male C57/6J mice (25-30 g) were obtained from the breeding facility of the University of São Paulo (São Paulo, Brazil) when they were 8 weeks old. The mice received standard laboratory chow and tap water ad libitum and were housed in temperature-controlled rooms $\left(22^{\circ} \mathrm{C}\right)$ under a 12:12-hr dark-light cycle. The Local Experimental Animal Committee approved all animal protocols (0944/09) and this investigation was conducted in accordance with the Principles of Laboratory Animal Care formulated by the National Institutes of Health (National Institutes of Health Publication No., 96-23, Revised 1996).

\section{Infarct surgery}

Anaesthetized mice $(50 \mathrm{mg} / \mathrm{kg}$ of ketamine and $10 \mathrm{mg} / \mathrm{kg}$ of xylazine, intraperitoneally) underwent to surgical occlusion of the left coronary artery, which resulted in MI. Briefly, after intubation, animals were positive-pressure ventilated with room air at 150 $\mathrm{mL}, 120$ breaths/min with a pressure-cycled rodent ventilator (Model 683, Harvard Apparatus, Holliston, MA, USA). For induction of MI of the left ventricle anterolateral wall, a lateral thoracotomy was performed in the third intercostal space, and the left anterior descending coronary artery was occluded with a nylon (6.0) (Ethicon Inc., Somerville, NJ, USA) suture at approximately $1 \mathrm{~mm}$ from its origin below the tip of the left atrium. The control (C) animals underwent the same procedures except that myocardial ischemia was not induced (Sham surgery). The chest was closed with a silk suture. Promptly, 24, 48, and $72 \mathrm{hr}$ after the surgery, a $0,5 \mathrm{mg} / \mathrm{kg}$ of morphine were injected into subcutaneous region for analgesia. The mortality rate of the animals undergoing this procedure was $25 \%$.

\section{Left ventricular function}

Sixty days after Sham or MI surgeries, echocardiographic evaluations were performed three times by a blinded observer, under the guidelines of the American Society of Echocardiography. Mice were anaesthetized (mixture of $0.5 \%-2 \%$ isoflurane and $98 \% \mathrm{O}_{2}$ at a flow rate of $1.5 \mathrm{~L} / \mathrm{min}$ ), and images were obtained with a $160-$ $\mathrm{Hz}$ linear transducer in a SEQUOIA 512 (Acuson Corporation, Mountain View, CA, USA) for measurements of parameters: LV ejection fraction (LVEF \%), left ventricular mass (LV mass), LV end-diameter during diastole (LVDD), LV end-diameter during systole, fractional shortening (FS), ejection fraction (EF), absolute isovolumetric relaxation time (IVRT); as described in detail elsewhere (Barboza et al., 2016).

The transducer was placed in the left anterolateral portion of the thorax, and the heart was imaged as a dimensional axial view of the LV with the mitral and aortic valves, as well as the apex, in the same image. The digital conversion of the image was obtained by a delimitation of the interventricular septum and the posterior 
wall of the LV. Additionally, an M-mode cursor was positioned perpendicular to the interventricular septum and the posterior wall of the LV at the level of the papillary muscles.

The initial evaluation was performed in order to evaluate LV ejection fraction to allocate the animals on the respective groups. After ET protocols or following, complete echocardiographic analyses were realized (after 8 weeks).

\section{Groups}

After the LVEF (\%) calculation, mice were randomly divided into three groups: (a) infarcted sedentary (IS; $\mathrm{n}=12)$; (b) infarcted MICT $(n=12)$ and (c) infarcted MIIT $(n=12)$. A fourth group, with no infarcted sedentary mice, was designed as a sedentary control group ( $S ; \mathrm{n}=12)$.

\section{Maximal exercise test and training protocols}

All animals were adapted to the maximal exercise test procedure with light exercise (i.e., $0.3 \mathrm{~km} / \mathrm{hr} ; 10 \mathrm{~min} /$ day) for 1 week. After $48 \mathrm{hr}$, animals underwent a maximal progressive exercise test on a motor-driven treadmill. Maximal progressive exercise test protocol consisted in a ramp protocol, which started with 0.3 $\mathrm{km} / \mathrm{hr}$ and increased progressively $0.3 \mathrm{~km} / \mathrm{hr}$ every 3 min until the animals are unable to run further- fatigue- , as described in detail in a previous publication (De Angelis et al., 2004). Exercise tolerance was recorded as the time that animals expend to reach the fatigue moment.

Before ET or adaptation protocols, all groups performed a regular warm-up exercise at $0.3 \mathrm{~km} / \mathrm{hr}$ for $3 \mathrm{~min}$. The MICT group performed ET on a motor treadmill at $60 \%$ of maximal running speed. The MIIT group performed ET in intervals, alternating between $4 \mathrm{~min}$ at $80 \%$ of maximal running speed and $4 \mathrm{~min}$ at $40 \%$ of maximal running speed. Physical exercise (PE) protocols were equalized by volume $(1 \mathrm{hr} / \mathrm{day})$ and intensity, meaning that the mean of the intensity performed by MICT (i.e., $30 \mathrm{~min}$ at $80 \%$ plus $30 \mathrm{~min}$ at $40 \%$ divided by two) was equal the intensity performed by MIIT. Therefore, both groups performed ET during $1 \mathrm{hr} /$ day, 5 days/week over 8 weeks. At the end of the 4th week, animals were reevaluated in the maximal progressive exercise test to adjust of exercise intensity.

\section{Hemodynamics}

Twenty-four hours after the final echocardiography procedures, mice were anesthetized (ketamine-xylazine $80: 40 \mathrm{mg} / \mathrm{kg}$ ) and polyethylene-tipped Tygon cannulas ( $4 \mathrm{~cm}$ of PE-08 connected to $2 \mathrm{~cm}$ of PE-50, Clay Adams) filled with heparinized saline were inserted into the carotid artery and jugular vein for direct measurements of arterial pressure (AP) and drug administration, respectively. The free ends of the cannulas were tunneled subcutaneously and exteriorized at the top of the skull. Two days after the catheter placement, hemodynamic measurements were made in conscious, freely moving mice. The arterial cannula was connected to a strain-gauge transducer (Blood Pressure XDCR, Kent Scientific, Litchfield, CT, USA), and AP signals were recorded during a 20-min period using a microcomputer equipped with an analog-to-digital converter (Windaq DI720, 4-kHz sampling frequency, Dataq Instruments). The recorded data were analyzed on a beat-to-beat basis to quantify changes in AP and heart rate (HR)

\section{Autonomic function}

Pulse interval (PI) and systolic arterial pressure (SAP) variability (HRV and blood pressure variability [BPV], respectively) were assessed in the time and frequency domains using autoregressive spectral analysis, as previously described. Briefly, PI, and SAP series were divided into segments of 350 beats and overlapped by $50 \%$. A spectrum was obtained for each of the segments via Levinson-Durbin recursion, with the model order chosen according to Akaike's criterion, ranging between 10 and 14 . The oscillatory components were quantified in the low- (LF, 0.1-1.0 Hz) and high-frequency ranges (HF, 1.0-5.0 Hz) (Soares et al., 2005). After coherence calculation, the alpha index was obtained from the square root of the ratio between R-R intervals and SBP variability in the LF two major bands (Mostarda et al., 2010).

Vagal and sympathetic function and intrinsic heart rate (IHR) were measured by determining the response to methylatropine (1 $\mathrm{mg} / \mathrm{kg}$ iv) and propranolol (1 $\mathrm{mg} / \mathrm{kg}$ intravenously) with a maximal injection volume of $40 \mu \mathrm{L}$ in a 2-day protocol. Because the HR responses to methylatropine and propranolol reach their peak in $3 \mathrm{~min}$, this time interval was used to quantify the drug-induced HR changes. On the first day of study, resting HR was recorded while the rats were in their home cages in an unrestrained state. After methylatropine injection, AP and HR were recorded for 3 min. Propranolol was injected 6 min after methylatropine, and the response was measured for $3 \mathrm{~min}$. The IHR was evaluated after the combined treatment with propranolol and methylatropine. On the second day, the sequence of injections was inverted, beginning with the propranolol injection. The methylatropine effect was evaluated as the difference between the maximum HR after methylatropine and the control HR. The propranolol effect was evaluated as the difference between the control HR and minimum HR produced after propranolol injection (De Angelis et al., 2004). 
Table 1. Autonomic tonus and autonomic modulation in time and frequency domain in S, IS, MICT, and MIIT groups

\begin{tabular}{|c|c|c|c|c|}
\hline Variable & $S(n=8)$ & $I S(n=6)$ & $\operatorname{MICT}(n=7)$ & $\mathrm{MIIT}(\mathrm{n}=7)$ \\
\hline HR (beats/min) & $554 \pm 9.18$ & $541 \pm 7.14$ & $539 \pm 10.2$ & $531 \pm 18$ \\
\hline $\operatorname{VarPI}\left(\mathrm{ms}^{2}\right)$ & $58 \pm 4.20$ & $33 \pm 8.09^{*}$ & $49 \pm 14.14$ & $54 \pm 6.50$ \\
\hline $\mathrm{LF}\left(\mathrm{ms}^{2}\right)$ & $8.35 \pm 1.70$ & $7.68 \pm 2.43$ & $6.08 \pm 0.65$ & $8.35 \pm 0.36$ \\
\hline$H F\left(m s^{2}\right)$ & $21.85 \pm 5.37$ & $4.49 \pm 0.7^{*}$ & $10.33 \pm 1.27$ & $19.00 \pm 1.46$ \\
\hline$\% \mathrm{LF}$ & $31 . \pm 2.44$ & $56 \pm 7^{*}$ & $37 \pm 0.88$ & $30 \pm 1.57$ \\
\hline$\% \mathrm{HF}$ & $69 . \pm 2.44$ & $44 \pm 7^{*}$ & $63 \pm 0.88$ & $70 \pm 1.57$ \\
\hline $\mathrm{LF} / \mathrm{HF}$ & $0.46 \pm 0.05$ & $1.68 \pm 0.56^{*}$ & $0.60 \pm 0.02$ & $0.44 \pm 0.03$ \\
\hline $\operatorname{VarSAP}\left(\mathrm{mmHg}^{2}\right)$ & $12 \pm 1.47$ & $17 \pm 4.89$ & $17 \pm 2.41$ & $9.00 \pm 1.89$ \\
\hline $\mathrm{LF}\left(\mathrm{mmHg}^{2}\right)$ & $3.3 \pm 0.47$ & $6.57 \pm 0.91^{*}$ & $3.52 \pm 0.7$ & $3.47 \pm 0.39$ \\
\hline Alpha index (ms/mmHg) & $1.69 \pm 0.09$ & $0.9 \pm 0.13^{*}$ & $1.34 \pm 0.09$ & $1.59 \pm 0.09$ \\
\hline IHR (beats/min) & $472 \pm 25$ & $490 \pm 4$ & $479 \pm 15$ & $441 \pm 16$ \\
\hline ST (beats/min) & $68 \pm 9$ & $122 \pm 10^{*}$ & $69 \pm 9^{\dagger}$ & $89 \pm 12^{\dagger}$ \\
\hline VT (beats/min) & $72 \pm 8$ & $48 \pm 4^{*}$ & $65 \pm 5$ & $68 \pm 3$ \\
\hline
\end{tabular}

Values are presented as mean \pm standard error.

S, sedentary control group; IS, infarcted sedentary group; MICT, infarcted moderate-intensity continuous endurance exercise training group; MIIT, infarcted high-intensity interval training group; HR, heart rate; VarPl, pulse interval variance; LF, low frequency band; HF, high frequency band; VarSAP, systolic arterial pressure variance; LF (mmHg), low frequency component of systolic blood pressure; IHR, intrinsic heart rate; ST, sympathetic tonus; $V T$, vagal tonus.

${ }^{*} P<0.05$ vs. S group. ${ }^{\dagger} P<0.05$ vs. IS group.

\section{Statistical analysis}

Data are expressed as mean \pm standard error. Analysis of variance (ANOVA) for repeated measures was used to compare the means between the groups at baseline and at the end of the protocol. In turn, to compare the means of the same variable, ANOVA oneway with the Tukey post hoc was performed. The significance level was established at $P \leq 0.05$.

\section{RESULTS}

\section{Exercise tolerance}

In the beginning of the protocol, results from maximal exercise test indicated elevated exercise tolerance in $S$ group (844.75 \pm $21.63 \mathrm{sec}$ ) in comparison with infarcted groups (IS, MCIT, and MIIT). However, further analysis did not demonstrate differences between IS $(618.67 \pm 27.95 \mathrm{sec})$, MICT $(663.73 \pm 20.48 \mathrm{sec})$ and MIIT (657.27 $\pm 53.27 \mathrm{sec})$. Comparisons pre-post exercise demonstrated increase in exercise tolerance in MICT (69.09\%) and MIIT (62.51\%) $(P<0.001$ for both). Results from both groups were superior to the observed in IS and S groups. However, there were no differences between MICT and MIIT.

\section{Echocardiographic measurements}

Results of echocardiographic evaluation are present in the Table 1 and Fig. 1. FS and EF were lower in the IS in comparison with S group. However, no significant differences were observed between
IS and trained infarcted groups (MICT and MIIT). On the other hand, MICT and MIIT showed higher CO and IVRT in comparison with IS groups, with no further differences between trained infarcted groups (Fig. 1). LV diameters during the systole (LVSD) and LVDD showed dissimilar results. Indeed, infarcted sedentary and trained groups demonstrated higher LVSD than S groups. Regarding LVDD, MICT, but no MIIT showed higher values in comparison with S group. Moreover, MI area and LV mass did not show the difference between the groups.

\section{Hemodynamic evaluation}

Results of hemodynamic evaluations are show in the Table 2. SAP, diastolic AP (DAP), mean AP (MAP), and BrS were reduced in IS group compared with $S$ group. Moreover, IS demonstrated lower values of DAP and MAP in comparison with MICT and MIIT. Both kinds of exercise were effective to reverse aforementioned alterations observed in IS groups to toward control group levels; thereby there were no differences between PE groups (i.e., MICT and MIIT) and S group regarding SAP, DAP, MAP, and $\mathrm{BrS}$, with $\mathrm{S}$ group.

\section{Autonomic function}

Results from autonomic function can be observed in Table 1. PI variance (VarPI) and its absolute $\left(\mathrm{ms}^{2}\right) \mathrm{HF}$ band, as well as its relative (\%) HF and LF bands, were altered in IS groups in comparison with $S$ group. As expected, these results cause changes on $\mathrm{LF} /$ 

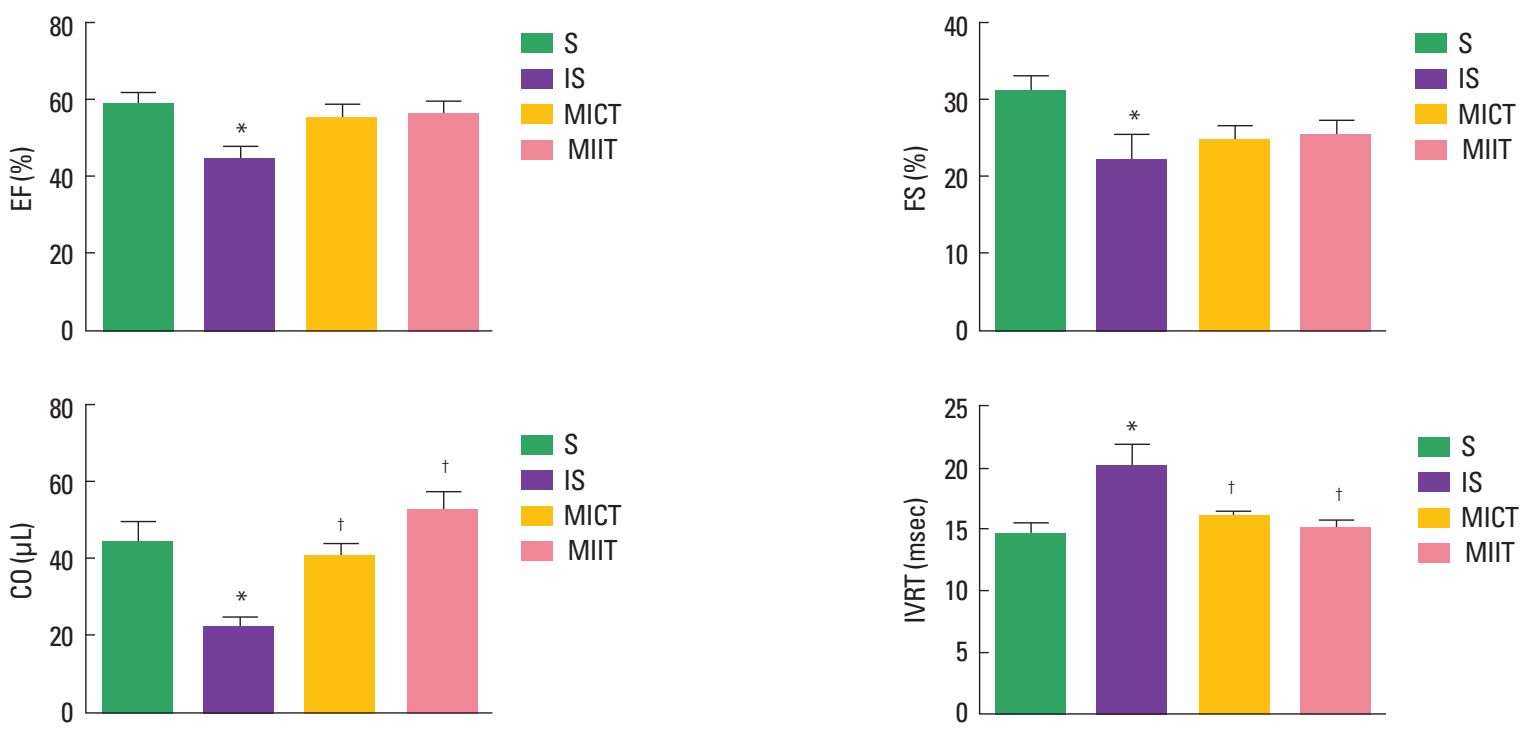

Fig. 1. Echocardiographic evaluations in sedentary (S), infarcted sedentary (IS), infarcted continuous training (MICT), and infarcted interval training (MIIT) groups. EF, ejection fraction; FS, fractional shortening; CO, cardiac output; IVRT, absolute isovolumetric relaxation time. ${ }^{*} P<0.05$ vs. S group. ${ }^{\dagger} P<0.05$ vs. IS group.

Table 2. Echocardiographic evaluations in S, IS, MICT, and MIIT groups

\begin{tabular}{|c|c|c|c|c|}
\hline Variable & $S(n=8)$ & IS $(n=6)$ & $\operatorname{MICT}(n=7)$ & MIIT $(n=7)$ \\
\hline Ml área (\%) & - & $35 \pm 3.6$ & $30 \pm 1.3$ & $34 \pm 2.4$ \\
\hline LV mass (mg) & $101 \pm 6$ & $122 \pm 14$ & $95 \pm 9$ & $106 \pm 19$ \\
\hline LVDD (mm) & $3.8 \pm 0.1$ & $3.8 \pm 0.2$ & $4.7 \pm 0.3^{*}$ & $4.6 \pm 0.3$ \\
\hline LVSD (mm) & $2.6 \pm 0.06$ & $3.11 \pm 0.14^{*}$ & $3.11 \pm 0.13^{*}$ & $3.2 \pm 0.27^{*}$ \\
\hline FS (\%) & $31.01 \pm 1.99$ & $22.06 \pm 1.88^{*}$ & $24.62 \pm 2.38$ & $25.20 \pm 2.21$ \\
\hline $\mathrm{CO}(\mu \mathrm{L})$ & $11 \pm 1.4$ & $5.4 \pm 0.7^{*}$ & $10 \pm 0.9^{\dagger}$ & $13 \pm 1.3^{\dagger}$ \\
\hline $\mathrm{EF}(\%)$ & $58.91 \pm 2.92$ & $44.55 \pm 3.30^{*}$ & $54.72 \pm 3.97$ & $55.93 \pm 3.73$ \\
\hline IVRT (ms) & $14.7 \pm 0.8$ & $20.2 \pm 1.7^{*}$ & $16 \pm 0.5^{\dagger}$ & $15 \pm 0.8^{\dagger}$ \\
\hline
\end{tabular}

Values are presented as mean \pm standard error of the mean.

S, sedentary control group; IS, infarcted sedentary group; MICT, infarcted moderate-intensity continuous endurance exercise training group; MIIT, infarcted high-intensity interval training group; MI, myocardial infarction; LV, left ventricular; LVDD, left ventricular diastolic diameter; LVSD, left ventricular systolic diameter; FS, fractional shortening; CO, cardiac output; EF, ejection fraction; IVRT, absolute isovolumetric relaxation time.

${ }^{*} P<0.05$ vs. S group. ${ }^{\dagger} P<0.05$ vs. IS group.

HF ratio, which was higher in IS groups when compared with S group. In turn, PE was able to reverse aforementioned alterations observed in IS groups to toward control group levels; thereby there were no differences between PE groups (i.e., MICT and MIIT) and S group regarding VarPI, absolute and relative HF and LF, as well as LF/HF.

In relation to SAP variance, its LF band-which represents the sympathetic outflow to the peripheral vessels - was increased in IS groups in comparison with $\mathrm{S}$ group. Again, both kinds of physical exercise reversed significantly this phenomenon to toward control group levels. Moreover, ST and VT were altered in IS groups. However, PE groups inhibit alteration on autonomic tonus, thereby there were no differences between PE groups (i.e.,
MICT and MIIT) and S group.

\section{DISCUSSION}

The present study demonstrated that 8 weeks of MICT and HIIT (MIIT) — equalized by exercise intensity and volume - are capable of improving equally exercise tolerance, hemodynamic and heart function, as well as autonomic control in MI mice.

Exercise intolerance is a clinical signal of MI, and its progression, concomitantly with the aggravation of $\mathrm{MI}$, can be associated with the skeletal myopathy observed in heart failure (Bacurau et al., 2016). Data of the present study indicate that 8 weeks of MICT and MIIT groups elicit a similar increase in exercise toler- 
ance in post-MI mice $(69.09 \%$ and $62.51 \%$, respectively).

Human experiments (Bacurau et al., 2016; Keteyian et al., 2014) and meta-analytic data (Elliott et al., 2015) from 6 clinical trials, which evaluated 229 patients, have been reporting superior effects of HIIT in comparison with MICT on exercise tolerance after MI. Regarding data from animal experiments, Moreira et al. (2013) investigated possible differences between two 8-week protocols of ET, to quote: a 49 min of moderate-intensity continuous aerobic exercise at $60 \%$ of maximal oxygen consumption $\left(\mathrm{VO}_{2 \max }\right)$ and a HIIT, composed by 7 cycles of 3 min of continuous aerobic exercise at $60 \%$ of $\mathrm{VO}_{2 \max }$ and a 4-min intervals at $85 \%$ of $\mathrm{VO}_{2 \max }$ (Moreira et al., 2013). Results showed that HIIT caused superior adaptations on aerobic capacity in comparison with MICT. Further analyses did not demonstrate differences in the adaptations of the elements associated with aerobic metabolism among the groups underwent to PE, since both increased equally citrate synthase and the cross-sectional area of type I muscle fiber. However, HIIT, but not MICT, caused significant increase in hexokinase maximal activity in the soleus, reflecting ameliorated functioning of anaerobic metabolism, as well as preserved muscle atrophy of type II fibers of plantaris muscle, which may be associated with a better muscular performance on the treadmill test (Moreira et al., 2013).

Accordingly, results of the present study disagree with data from human (Elliot et al., 2015) and rodents (Moreira et al., 2013) and indicate that programs of ET (i.e., HIIT and moderate-intensity continuous) equalized by total intensity and volume elicit similar improvements in exercise tolerance. Despite the equalization of the variables (i.e., exercise intensity and volume) of ET, other factors, such as the intensity of HIIT prescription, can be responsible for the superior response of exercise tolerance after HIIT observed by Moreira et al. (2013). Indeed, the volume of the session did not seem to be a key factor in the aerobic adaptive response from HIIT, once, in the present study, we performed a larger session (60 min) than Moreira et al. (2013) (49 min). On the other hand, our animals were undergoing to a slightly lighter session of HIIT ( $80 \%$ vs. $85 \%$ ).

Since the organization of the variables of PE is a determinant factor in the human organic response from HIIT (Gibala et al., 2012; Moreira et al., 2013), is possible that the higher exercise intensity performed by rodents from Moreira et al. (2013) stimulated anabolic pathways responsible for skeletal muscle mass regulation (Coelho-Junior et al., 2016; Holm et al., 2008), preventing muscle atrophy and, at the end, higher exercise tolerance. On the other hand, the intensity performed in the present investigation was probably not enough to elicit muscle mass maintaining.
Therefore, in front of the present data, is possible suggest that differences in the intensities of HIIT programs can cause different metabolic and muscular adaptations in MI rodents, indicating that more studies are still necessary about the effects of HIIT on exercise tolerance after MI.

In relation to the hemodynamic evaluations, interestingly, data of the present study indicate that IS group showed lower values of SAP, DAP, and MAP than S and trained MI groups. This response may be partly explained by impaired ventricular function - once IS group presented decreased $\mathrm{CO}$ - accompanied by significant alteration on FS and EF-, in comparison with the other groups. Moreover, is possible observe that IS animals showed decreased $\mathrm{BrS}$ (i.e., alpha-index) and increased autonomic imbalance, indicated by increased vascular sympathetic modulation (\% LF of PI) and vascular tonus, which were not enough to counteracting cardiovascular dysfunction and restores $\mathrm{CO}$, following by decreased cardiac parasympathetic modulation (absolute and relative [\%] HF of PI) and vagal tonus.

Several evidence corroborate with data of the present study and indicate that $\mathrm{MI}$ is associated with decreased hemodynamic response (i.e., SAP, DAP, MAP, and BrS) and ventricular function (i.e., FS, EF, LVSD), concomitant with autonomic dysfunction in favor of sympathetic activity (Jorge et al., 2011; Mostarda et al., 2010; Rodrigues et al., 2014a; Rodrigues et al., 2014b). This phenomenon seems to occur due to neurohumoral excitation, which represents an initial response of the organic system to $\mathrm{MI}$ in an attempt to stabilize $\mathrm{CO}$, avoiding impairment of blood flow to the tissues (Jorge et al., 2011; Rodrigues et al., 2014a). However, the progression of $\mathrm{MI}$ is accompanied by chronical neurohumoral excitation leading to deleterious effects and, consequently, poor prognosis (Jorge et al., 2011; Rodrigues et al., 2014a).

$\mathrm{BrS}$ impairment has been indicating as the main, or, at least, one of the main responsible for suppressed sympathoinhibition observed in MI, inducing altered heart and peripheral hemodynamic functioning (Mostarda et al., 2010; Mostarda et al., 2014; Rodrigues et al., 2014a). Furthermore, evidence are not limited to the relation between $\mathrm{BrS}$ and overall hemodynamic control, but data for our group suggesting that BrS dysfunction can further impair cardiac functioning (i.e., ventricular function) due changes on cardiac proteins involved in calcium intracellular homeostasis (i.e., SERCA2 and NCX) and proinflammatory process (Mostarda et al., 2010; Mostarda et al., 2014; Rodrigues et al., 2014a; Rodrigues et al., 2014b). Therefore, data of the present study indicate that IS group presents a classical MI phenotype observed in other rodents (e.g., rats) once impairment on $\mathrm{BrS}$ collaborates 
with autonomic dysfunction causing ventricular dysfunction.

Regarding the effects of ET, data of the present study indicate the both protocols of ET-moderate-intensity continuous endurance and HIIT—were equally effective to reverse hemodynamic, functional and autonomic dysfunctions observed in IS, causing changes toward control group levels (i.e., S group). Moreover, such as observed on exercise tolerance, results did not demonstrate differences between the ET groups.

Data of the present study are confluent with several evidence, which have been indicating that MICT is profitable to counteracting the deleterious effects of MI on cardiac function, hemodynamic and autonomic control in rodents (Barboza et al., 2013; Jorge et al., 2011; Rodrigues et al., 2014a; Rodrigues et al., 2014b). Moreover, since the seminal experiment of Wisløff et al. (2007), which showed superior effects of HIIT in the LV remodeling, systolic and diastolic function of cardiac patients in comparison with MICT, studies have been conducted and also observed beneficial effects of HIIT in rodents (Lu et al., 2015; Moreira et al., 2013). Therefore, taken data together, is possible infer that both kinds of exercise can be effective to reverse impaired cardiac function, as well as hemodynamic and autonomic dysfunctions, observed in MI-mice, consequently, improving mortality rate.

However, to the best of our knowledge, just one study compared both kinds of exercise; however, the study was developed in rats (Moreira et al., 2013). Thereby, as far as the literature is concerned, this article was the first one to compare an interval with a MICT in ischemic MI mice. Interestingly, as aforementioned, Moreira et al. (2013) showed superior effects on exercise tolerance after HIIT in comparison with MICT. Nevertheless, as in the present study, data demonstrated that both groups elicited similar improvements in cardiac function in response to both kinds of exercises. Thus, in conjunction with Moreira et al. (2013), evidence in rodents did not support the superior effect of HIIT on cardiac function, hemodynamic and autonomic control.

Since the main differences between our protocol and the protocol of Moreira et al. (2013) are the intensity prescribed to HIIT, unlike the exercise tolerance, which seems to be influenced by HIIT intensity, cardiac function, hemodynamic and autonomic control did not seem to be intensity-dependent. In the classical protocol of Wisløff et al. (2007), patients were undergone to twelve weeks of exercise. Therefore, is possible that larger time of interventions would collaborate to larger effects of HIIT. Thus, future studies should be designed with a larger time of intervention.

In conclusion, data of the present study indicate that MI leads to impairment of exercise tolerance, cardiac function, hemody- namic and autonomic control. On the other hand, both kinds of physical exercise were effective to reverse the cardiac and autonomic deleterious effects of MI.

\section{CONFLICT OF INTEREST}

No potential conflict of interest relevant to this article was reported.

\section{ACKNOWLEDGMENTS}

BR, KDA, MCI received financial support from Conselho Nacional de Pesquisa e Desenvolvimento (CNPq-BPQ). The authors are also grateful to the Coordenação de Aperfeiçoamento de Pessoal de Nível Superior (CAPES) for the scholarship to HJCJ and CCCA.

\section{REFERENCES}

Alpert JS, Thygesen K, Antman E, Bassand JP. Myocardial infarction redefined--a consensus document of The Joint European Society of Cardiology/American College of Cardiology Committee for the redefinition of myocardial infarction. J Am Coll Cardiol 2000;36:959-969.

Anand SS, Islam S, Rosengren A, Franzosi MG, Steyn K, Yusufali AH, Keltai M, Diaz R, Rangarajan S, Yusuf S; INTERHEART Investigators. Risk factors for myocardial infarction in women and men: insights from the INTERHEART study. Eur Heart J 2008;29:932-940.

Bacurau AV, Cunha TF, Souza RW, Voltarelli VA, Gabriel-Costa D, Brum PC. Aerobic Exercise and Pharmacological Therapies for Skeletal Myopathy in Heart Failure: Similarities and Differences. Oxid Med Cell Longev 2016;2016:4374671.

Barboza CA, Rocha LY, Mostarda CT, Figueroa D, Caperuto EC, De Angelis $\mathrm{K}$, Irigoyen $\mathrm{MC}$, Rodrigues B. Ventricular and autonomic benefits of exercise training persist after detraining in infarcted rats. Eur J Appl Physiol 2013;113:1137-1146.

Barboza CA, Souza GI, Oliveira JC, Silva LM, Mostarda CT, Dourado PM, Oyama LM, Lira FS, Irigoyen MC, Rodrigues B. Cardioprotective Properties of Aerobic and Resistance Training Against Myocardial Infarction. Int J Sports Med 2016;37:421-430.

Caspersen CJ, Powell KE, Christenson GM. Physical activity, exercise, and physical fitness: definitions and distinctions for health-related research. Public Health Rep 1985;100:126-131.

Coelho-Junior HJ, Gambassi BB, Diniz TA, Fernandes IM, Caperuto ÉC, Uchida MC, Lira FS, Rodrigues B. Inflammatory mechanisms associated with skeletal muscle sequelae after stroke: role of physical exer- 
cise. Mediators Inflamm 2016;2016:3957958.

De Angelis K, Wichi RB, Jesus WR, Moreira ED, Morris M, Krieger EM, Irigoyen MC. Exercise training changes autonomic cardiovascular balance in mice. J Appl Physiol (1985) 2004;96:2174-2178.

Elliott AD, Rajopadhyaya K, Bentley DJ, Beltrame JF, Aromataris EC. Interval training versus continuous exercise in patients with coronary artery disease: a meta-analysis. Heart Lung Circ 2015;24:149-157.

Finegold JA, Asaria P, Francis DP. Mortality from ischaemic heart disease by country, region, and age: statistics from World Health Organisation and United Nations. Int J Cardiol 2013;168:934-945.

Fletcher GF, Ades PA, Kligfield P, Arena R, Balady GJ, Bittner VA, Coke LA, Fleg JL, Forman DE, Gerber TC, Gulati M, Madan K, Rhodes J, Thompson PD, Williams MA; American Heart Association Exercise, Cardiac Rehabilitation, and Prevention Committee of the Council on Clinical Cardiology, Council on Nutrition, Physical Activity and Metabolism, Council on Cardiovascular and Stroke Nursing, and Council on Epidemiology and Prevention. Exercise standards for testing and training: a scientific statement from the American Heart Association. Circulation 2013;128:873-934.

Garza MA, Wason EA, Zhang JQ. Cardiac remodeling and physical training post myocardial infarction. World J Cardiol 2015;7:52-64.

Gibala MJ, Little JP, Macdonald MJ, Hawley JA. Physiological adaptations to low-volume, high-intensity interval training in health and disease. J Physiol 2012;590:1077-1084.

Hamm LF, Wenger NK, Arena R, Forman DE, Lavie CJ, Miller TD, Thomas RJ. Cardiac rehabilitation and cardiovascular disability: role in assessment and improving functional capacity: a position statement from the American Association of Cardiovascular and Pulmonary Rehabilitation. J Cardiopulm Rehabil Prev 2013;33:1-11.

Holm L, Reitelseder S, Pedersen TG, Doessing S, Petersen SG, Flyvbjerg A, Andersen JL, Aagaard P, Kjaer M. Changes in muscle size and MHC composition in response to resistance exercise with heavy and light loading intensity. J Appl Physiol (1985) 2008;105:1454-1461.

Jorge L, Rodrigues B, Rosa KT, Malfitano C, Loureiro TC, Medeiros A, Curi R, Brum PC, Lacchini S, Montano N, De Angelis K, Irigoyen MC. Cardiac and peripheral adjustments induced by early exercise training intervention were associated with autonomic improvement in infarcted rats: role in functional capacity and mortality. Eur Heart J 2011;32:904-912.

Keteyian SJ, Hibner BA, Bronsteen K, Kerrigan D, Aldred HA, Reasons LM, Saval MA, Brawner CA, Schairer JR, Thompson TM, Hill J, McCulloch D, Ehrman JK. Greater improvement in cardiorespiratory fitness using higher-intensity interval training in the standard cardiac rehabilitation setting. J Cardiopulm Rehabil Prev 2014;34:98-105.

Kleiger RE, Miller JP, Bigger JT Jr, Moss AJ. Decreased heart rate variabili- ty and its association with increased mortality after acute myocardial infarction. Am J Cardiol 1987;59:256-262.

La Rovere MT, Bigger JT Jr, Marcus FI, Mortara A, Schwartz PJ. Baroreflex sensitivity and heart-rate variability in prediction of total cardiac mortality after myocardial infarction. ATRAMI (Autonomic Tone and Reflexes After Myocardial Infarction) Investigators. Lancet 1998;351: 478-484.

Lu K, Wang L, Wang C, Yang Y, Hu D, Ding R. Effects of high-intensity interval versus continuous moderate-intensity aerobic exercise on apoptosis, oxidative stress and metabolism of the infarcted myocardium in a rat model. Mol Med Rep 2015;12:2374-2382.

Maiorana A. Interval training confers greater gains than continuous training in people with heart failure. J Physiother 2012;58:199.

Mezzani A, Hamm LF, Jones AM, McBride PE, Moholdt T, Stone JA, Urhausen A, Williams MA; European Association for Cardiovascular Prevention and Rehabilitation; American Association of Cardiovascular and Pulmonary Rehabilitation; Canadian Association of Cardiac Rehabilitation. Aerobic exercise intensity assessment and prescription in cardiac rehabilitation: a joint position statement of the European Association for Cardiovascular Prevention and Rehabilitation, the American Association of Cardiovascular and Pulmonary Rehabilitation and the Canadian Association of Cardiac Rehabilitation. Eur J Prev Cardiol 2013;20:442-467.

Moreira JB, Bechara LR, Bozi LH, Jannig PR, Monteiro AW, Dourado PM, Wisløff U, Brum PC. High- versus moderate-intensity aerobic exercise training effects on skeletal muscle of infarcted rats. J Appl Physiol (1985) 2013;114:1029-1041.

Mostarda C, Rodrigues B, Medeiros A, Moreira ED, Moraes-Silva IC, Brum PC, Angelis KD, Irigoyen MC. Baroreflex deficiency induces additional impairment of vagal tone, diastolic function and calcium handling proteins after myocardial infarction. Am J Transl Res 2014;6: 320-328.

Mostarda C, Rodrigues B, Vane M, Moreira ED, Rosa KT, Moraes-Silva IC, Lacchini S, Casarini DE, De Angelis K, Irigoyen MC. Autonomic impairment after myocardial infarction: role in cardiac remodelling and mortality. Clin Exp Pharmacol Physiol 2010;37:447-452.

Nunes RB, Alves JP, Kessler LP, Dornelles AZ, Stefani GP, Lago PD. Interval and continuous exercise enhances aerobic capacity and hemodynamic function in CHF rats. Braz J Phys Ther 2015;19:257-263.

Pattyn N, Vanhees L, Cornelissen VA, Coeckelberghs E, De Maeyer C, Goetschalckx K, Possemiers N, Wuyts K, Van Craenenbroeck EM, Beckers PJ. The long-term effects of a randomized trial comparing aerobic interval versus continuous training in coronary artery disease patients: 1-year data from the SAINTEX-CAD study. Eur J Prev Cardiol 2016;23:1154-1164. 
Pinho CA, Tromm CB, Tavares AM, Silva LA, Silveira PC, Souza CT, Benetti M, Pinho RA. Effects of different physical training protocols on ventricular oxidative stress parameters in infarction-induced rats. Life Sci 2012;90:553-559.

Rodrigues B, Lira FS, Consolim-Colombo FM, Rocha JA, Caperuto EC, De Angelis K, Irigoyen MC. Role of exercise training on autonomic changes and inflammatory profile induced by myocardial infarction. Mediators Inflamm 2014a;2014:702473.

Rodrigues B, Santana AA, Santamarina AB, Oyama LM, Caperuto ÉC, de Souza CT, Barboza Cde A, Rocha LY, Figueroa D, Mostarda C, Irigoyen MC, Lira FS. Role of training and detraining on inflammatory and metabolic profile in infarcted rats: influences of cardiovascular autonomic nervous system. Mediators Inflamm 2014b;2014:207131.

Rodrigues F, Feriani DJ, Barboza CA, Abssamra ME, Rocha LY, Carrozi NM, Mostarda C, Figueroa D, Souza GI, De Angelis K, Irigoyen MC, Rodrigues B. Cardioprotection afforded by exercise training prior to myocardial infarction is associated with autonomic function improvement. BMC Cardiovasc Disord 2014c;14:84.

Soares PP, Moreno AM, Cravo SL, Nóbrega AC. Coronary artery bypass surgery and longitudinal evaluation of the autonomic cardiovascular function. Crit Care 2005;9:R124-131.

Tarnavski O, McMullen JR, Schinke M, Nie Q, Kong S, Izumo S. Mouse cardiac surgery: comprehensive techniques for the generation of mouse models of human diseases and their application for genomic studies. Physiol Genomics 2004;16:349-360.

Thygesen K, Alpert JS, Jaffe AS, Simoons ML, Chaitman BR, White HD; Joint ESC/ACCF/AHA/WHF Task Force for Universal Definition of Myocardial Infarction; Authors/Task Force Members Chairpersons, Thygesen K, Alpert JS, White HD; Biomarker Subcommittee, Jaffe AS, Katus HA, Apple FS, Lindahl B, Morrow DA; ECG Subcommittee, Chaitman BR, Clemmensen PM, Johanson P, Hod H; Imaging Sub- committee, Underwood R, Bax JJ, Bonow JJ, Pinto F, Gibbons RJ; Classification Subcommittee, Fox KA, Atar D, Newby LK, Galvani M, Hamm CW; Intervention Subcommittee, Uretsky BF, Steg PG, Wijns W, Bassand JP, Menasche P, Ravkilde J; Trials \& Registries Subcommittee, Ohman EM, Antman EM, Wallentin LC, Armstrong PW, Simoons ML; Trials \& Registries Subcommittee, Januzzi JL, Nieminen MS, Gheorghiade M, Filippatos G; Trials \& Registries Subcommittee, Luepker RV, Fortmann SP, Rosamond WD, Levy D, Wood D; Trials \& Registries Subcommittee, Smith SC, Hu D, Lopez-Sendon JL, Robertson RM, Weaver D, Tendera M, Bove AA, Parkhomenko AN, Vasilieva EJ, Mendis S; ESC Committee for Practice Guidelines (CPG), Bax JJ, Baumgartner H, Ceconi C, Dean V, Deaton C, Fagard R, Funck-Brentano C, Hasdai D, Hoes A, Kirchhof P, Knuuti J, Kolh P, McDonagh T, Moulin C, Popescu BA, Reiner Z, Sechtem U, Sirnes PA, Tendera M, Torbicki A, Vahanian A, Windecker S; Document Reviewers, Morais J, Aguiar C, Almahmeed W, Arnar DO, Barili F, Bloch KD, Bolger AF, Botker HE, Bozkurt B, Bugiardini R, Cannon C, de Lemos J, Eberli FR, Escobar E, Hlatky M, James S, Kern KB, Moliterno DJ, Mueller C, Neskovic AN, Pieske BM, Schulman SP, Storey RF, Taubert KA, Vranckx P, Wagner DR. Third universal definition of myocardial infarction. J Am Coll Cardiol 2012;60:1581-1598.

Tschentscher M, Eichinger J, Egger A, Droese S, Schönfelder M, Niebauer J. High-intensity interval training is not superior to other forms of endurance training during cardiac rehabilitation. Eur J Prev Cardiol 2016;23:14-20.

Wisløff U, Støylen A, Loennechen JP, Bruvold M, Rognmo Ø, Haram PM, Tjønna AE, Helgerud J, Slørdahl SA, Lee SJ, Videm V, Bye A, Smith GL, Najjar SM, Ellingsen Ø, Skjaerpe T. Superior cardiovascular effect of aerobic interval training versus moderate continuous training in heart failure patients: a randomized study. Circulation 2007;115:30863094. 